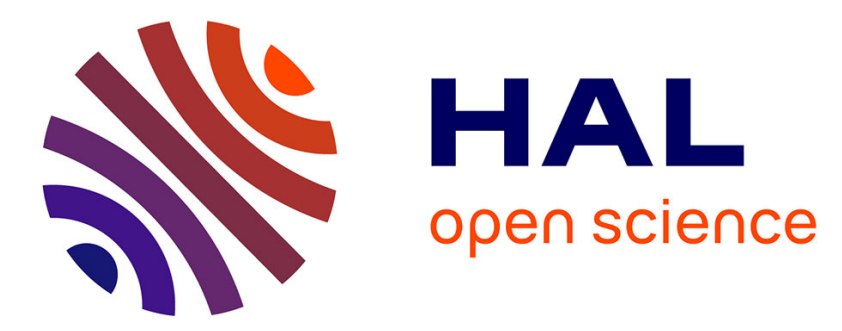

\title{
Instability is the norm! A physics-based theory to navigate among risks and opportunities
}

Frederick Benaben, Louis Faugere, Benoit Montreuil, Matthieu Lauras, Nafe Moradkhani, Thibaut Cerabona, Juanqiong Gou, Wenxin Mu

\section{- To cite this version:}

Frederick Benaben, Louis Faugere, Benoit Montreuil, Matthieu Lauras, Nafe Moradkhani, et al.. Instability is the norm! A physics-based theory to navigate among risks and opportunities. Enterprise Information Systems, 2022, 16 (6), pp.980-1007. 10.1080/17517575.2021.1878391 . hal-03121248

\section{HAL Id: hal-03121248 \\ https://imt-mines-albi.hal.science/hal-03121248}

Submitted on 27 Jan 2021

HAL is a multi-disciplinary open access archive for the deposit and dissemination of scientific research documents, whether they are published or not. The documents may come from teaching and research institutions in France or abroad, or from public or private research centers.
L'archive ouverte pluridisciplinaire HAL, est destinée au dépôt et à la diffusion de documents scientifiques de niveau recherche, publiés ou non, émanant des établissements d'enseignement et de recherche français ou étrangers, des laboratoires publics ou privés. 


\title{
Instability is the norm! A physics-based theory to navigate among risks and opportunities
}

\author{
Frederick Benaben (D) ${ }^{a}$, Louis Faugere ${ }^{b}$, Benoit Montreuil $\mathbb{D D}^{b}$, Matthieu Lauras (D) $^{a}$, \\ Nafe Moradkhani ${ }^{\mathrm{a}, \mathrm{b}}$, Thibaut Cerabona ${ }^{\mathrm{a}, \mathrm{b}}$, Juanqiong Gou ${ }^{\mathrm{c}}$ and Wenxin $\mathrm{Mu}^{\mathrm{c}}$ \\ aCentre Génie Industriel, IMT Mines Albi, Université de Toulouse - Campus Jarlard, Route De Teillet, Albi - \\ France; ${ }^{b}$ Physical Internet Center, H. Milton Stewart School of Industrial and Systems Engineering, Georgia \\ Institute of Technology, GA, USA; 'Department of Information Management - School of Economics and \\ Management, Beijing Jiaotong University - 3, Shangyuancun Xizhimenwai - Beijing, China
}

\begin{abstract}
Most decision-supports methods are dedicated to the identification and characterization of risks and opportunities. The concrete exploitation of these risks and opportunities is generally depending on the ability of users to analyze multi-dimensional situations, to mobilize their experience and to foresee consequences. In this article, a new and original data science-based vision of risk and opportunity management for decision-making purpose is introduced. The main expected benefit of this vision is to enable decision makers to manage the performance trajectory of a considered system by visualizing and combining the impact of risks and opportunity.
\end{abstract}

\section{KEYWORDS}

Risk management; risks; opportunity; artificial intelligence; physics; force fields; system modelling; decision support

\section{Introduction}

Dealing with instability (of a system or its environment) is a key expectation for decision makers. This article aims at presenting an innovative decision-making vision through performance management. There are a lot of existing tools and approaches dedicated to performance management and decision making (SWOT, Simulation, Business Intelligence, Activity Based Costing, Balanced Scorecard, Risk Management, Multi-Criteria Decision Making, etc.) but none of them deals at the same time with (i) the understanding of the observed system and its environment, (ii) the understanding of the potential consequences of changes, and (iii) the understanding of the choice mechanisms among the available options. Most of them deal with one or two of these three dimensions (and are therefore very interesting in the perspective of contributing to the whole approach as components of the dynamicity of the framework). The preliminary assertion at the root of this article is the following: instability is the norm (Taleb 2007), (Taleb 2012), (Ribeiro and Barbosa-Povoa 2018). Instability can be defined from the Cambridge Dictionary as

CONTACT Frederick BenabenEmail frederick.benaben@mines-albi.fr @ Centre Génie Industriel, IMT Mines Albi, Université De Toulouse - Campus Jarlard, Route De Teillet - 81000 Albi - FranceLouis Faugere; $\bigotimes$ wxmu@bjtu.edu.cn $\bigoplus$ Physical Internet Center H. Milton Stewart School of Industrial and Systems Engineering - 755 Ferst Dr. NW. Atlanta GA 30332 - United States of AmericaMatthieu; Lauraslouis.faugere@gatech.edu @ Department of Information Management - School of Economics and Management Beijing Jiaotong University - 3, Shangyuancun Xizhimenwai Beijing, 100044 - China 
'uncertainty caused by the possibility of a sudden change in the present situation' ${ }^{1}$ where uncertainty could be referred as 'a situation in which something is not known or something that is known is not certain' ${ }^{2}$ and one major component of Risk management as presented in (Bastin, et al., 2013). Actually, there is currently no point in aiming at stability for social or economic systems. The key goal of management is to benefit from instability and move forward in a continuously instable way. Based on this preliminary assertion, the contradiction is that, on the one hand controlling instability is a truly key ambition for the management of socio-economic systems, and, on the other hand, the management tools, dedicated to support decision makers by dealing with their data, information and knowledge are commonly dashboards mostly devoted to visualisation only. These tools are clearly captivating and amazing; however, they are only dedicated to arranging the available information in a way that can be managed by human beings. The required additional activity to provide the decision makers with deeper insights and tangible analysis is still quite in its infancy. The major objective of this article is to describe a theoretical framework for decision-making, dedicated to the management of risks and opportunities, modelled as physical forces that may deviate the performance trajectory of systems.

The logical structure of this paper is based on the two following complementary milestones:

First, it describes a theoretical framework for decision making in which a new paradigm of risks and opportunities management can be deployed.

Second, it defines practically the different concrete steps within the previously defined theoretical framework to support decision-making.

About the first point, the vision is to provide a framework dedicated to describe the way to climb the abstraction layers from raw data (lowest level) to decision (highest level) through information (intermediary level). The principle is to interpret data automatically and significantly enough to generate (and maintain) information that can be relevant for the decision support process about the considered system. That vision is really about the usage of data in a way that is constructive for the decision, and in a way that defines more precisely the shape of what Artificial Intelligence could be capable of.

About the second point, the vision is that managing a system implies to target some goals, which are generally represented by KPIs (obviously, there might be some qualitative objectives that may not be represented with numerical KPIs, but fundamentally, that is minority). Consequently, managing a system is intended to try to bring its KPIs as close as possible to some target values. ${ }^{3}$ So, roughly speaking, the management of a system can be seen as targeting the control of the trajectory of that system within the dimensions of its KPIs. These KPIs evolve due to the occurrence of potentialities, which then become actualities, and change the values of the KPIs (e.g. the occurrence of a risk may decrease the quality of my product, or the occurrence of an opportunity may improve my production capacity). As presented in (Olsson 2007), risks and opportunities are finally quite close concepts. They can be seen as symmetric notions (pushing or pulling the observed system closer or farer from its target KPIs values). Roughly speaking, if the consequences of an actuality are making the KPIs closer to their targeted values, then that potentiality should be considered as an opportunity. Symmetrically, if the consequences of an actuality are 
moving the KPIs away from their objective values, then, the potentiality can be seen as a risk. So, risks and opportunities are seen relatively to the considered system's point of view. It means that a risk is indeed negative from the system's point of view only (because if it occurs, it will downgrade KPIs). Similarly, opportunities are considered positive because, still from the system's point of view, they would improve its KPIs. However, and obviously, a potentiality could be a risk from one's point of view and an opportunity from another's point of view. In addition, and more subtlety, some opportunities (resp. risks) may finally have negative (resp. positive) consequences on the KPIs. However, from the perspective of this research works, it may be due to a wrong preliminary evaluation of the potentiality, and more probably, to a wrong decomposition of the potentiality: it actually might correspond to two actual imbricated potentialities: one opportunity and the associated risk (or even a larger group of conjunct risks and opportunities). The negative consequences are finally the consequence of this associated risk. So, these merged potentialities should be separated.

The fundamental analogy used by this article is to see opportunities and risks as physical forces applied onto the considered system within the framework of its KPIs. However, following that metaphor, there are at least two steps that must be defined: (i) how can the data about the observed situation (and the observed system) be used to identify and model risks and opportunities as physical forces within the framework of the KPIs? And (ii) how can these identified and modelled forces be used to support decisionmaking with regards to the observed situation and system?

The question about the theoretical framework and both the questions about the two steps within the framework will be studied from the perspective of the literature review first, then the proposal will be introduced, illustrated and discussed. Thus, the structure of this article is the following: After this introduction, in the second section, the background on decision-making in management science and opportunity and risk management is studied, just before introducing the conjectural framework based on a review of the related work. Third, the approach is presented in two layers (covering the two mentioned steps). Four, a fictional example is provided to try to show simply and illustratively the specific contributions. Five, a discussion section presents advantages and limitations, as well as avenues of practical applications. Finally, the concluding section presents the main takeaways of the article and some significant perspectives.

\section{State of the art and related works}

This section is dedicated to study the way previous research contributions have studied and addressed the issue of decision-making and performance management. Mainly, the question is about controlling a system within an instable context. Based on this statement, this section is organised according to two main subsections. The first one concerns contributions extracted from the risk (and opportunity) sciences and management sciences. These domains are definitely great contributors as they deal with the way risks could be studied and handled to control a system potentially facing these factors of instability in a moving environment. They are also dedicated to provide managers and decision-makers with the appropriate technics and tools for succeeding in their roles and performing in reaching their goals in an instable environment. The second subsection is related to the question of the theoretical framework. Basically, this subsection aims at 
studying the process of decision from the perspectives of data and information management. Roughly speaking, the goal is to theoretically structure the process of decision in a way that can be populated with the considerations extracted from the first subsection.

\subsection{Decision and management in uncertain environment}

System management and decision-making in uncertain environment require to comprehend available options and the associated triggering decisions or uncontrollable events. These options, manageable or uncontrollable can be considered as opportunities and risks. Even if opportunities and risks can be seen as very similar concepts (Olsson 2007), the specific domain of risk management is clearly more advanced. This statement is concretely not a concern because most results regarding risk management can be extended to opportunity management thanks to their symmetry. As a consequence, this subsection mainly focuses on research contributions and scientific results coming from risk management but roughly speaking, these results can be considered as accurate regarding the broader domain of potentiality management.

\subsubsection{General background}

During the past decades, the domain of risk management has provided several admitted results that are nowadays considered as stable contributions. First, the process of risk management is usually presented according to three or four main steps (the fourth step might be omitted) as presented in (Ho et al. 2015) and (White 1995):

Risk identification: that first phase focuses on studying the system and its context to detect and identify risks that are relevant to the system.

Risk assessment/evaluation: That second phase aims at measuring each risk and providing tangible values to its main characteristics (impact, probability, etc.).

Risk mitigation: This third phase aims at identifying measures and actions dedicated to control and limit the unfortunate consequences of the risk.

Monitoring of the situation: the fourth and final phase aims at supervising the situation to perform detection of risks (thus controlling the waterfall cycle).

Second, the standard model of risk is generally described as follows (or based on the same paradigm): As described in (Edwards and Bowen 2005) risk is admittedly seen as the combination of the severity of the effects on the system on the one hand and its probability of occurrence on the other hand. This model can obviously be extended to the concept of opportunity: The severity of the effects can be seen as the negative (impact of a risk) or positive (benefit of an opportunity) consequences on the system's KPIs. The potentiality is then characterised by its probability multiplied by its effect, as shown in (Benaben, et al., 2019a) and on Figure 1:

This model is a very standard two-dimension vision of risks. It is mostly used to visualise and to prioritise risks to identify and define mitigation measures. Some recent contribu-tions have clearly improved that vision, for instance by including Bayesian consideration as presented in (Zheng and Zhang 2020).

Considering the previous elements, this article suggests to extend the four phases of risk (only) management to risk and opportunity management. The two first phases 


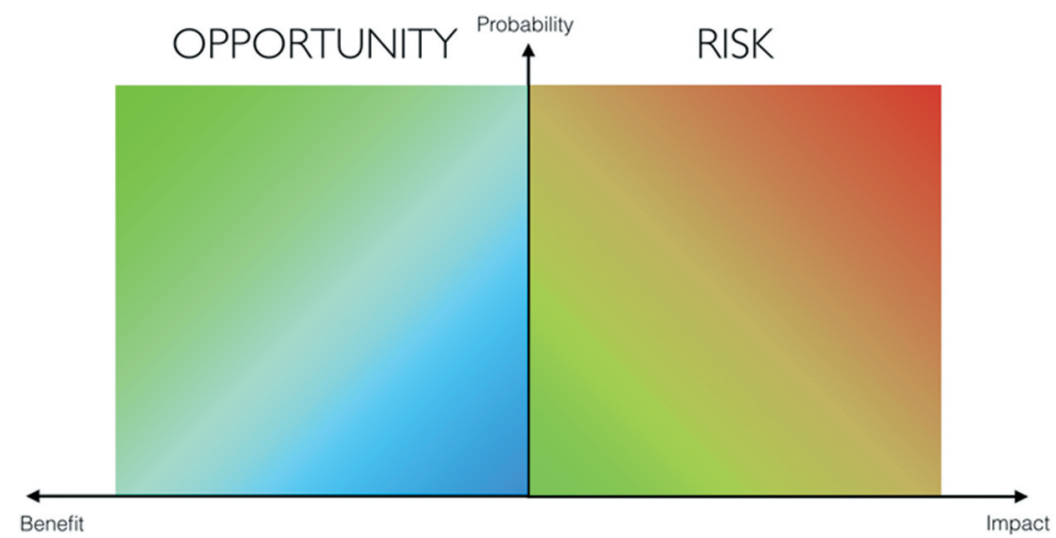

Figure 1. Classical two-dimension vision of Opportunity and Risk.

(identification and assessment) can be considered as generic (because they are the same for risks and opportunities) and grouped in a single step: risk and opportunity detection and modelling. The third and fourth phases (mitigation and monitoring) are different for risks and opportunities and could be grouped in a second step: decision making for trajectory control.

\subsubsection{Contributions from risk management techniques}

Risk management is a largely studied domain and there are a lot of well-known and broadly used techniques. (White 1995) provided a very comprehensive literature review from which the following techniques can be primarily extracted:

Failure Mode and Effects Analysis (FMEA) (Clifton 1990): This approach is based on the study of all the components of a system and on the identification for each of them of all the potential failure modes, including the specific consequences on the considered system. Finally, these potential consequences are ranked in a table which structure is close to the one of Figure 1.

Fault Tree Analysis and Event Tree Analysis (FTA and ETA) (Bell 1989): For that approach, analysts are required to model, either causes (backward with FTA) or effects (forward with ETA) of failures. These models are generally represented as logic diagrams, which can then be used for decision-making.

Hazard and Operational study (HAZOP) (Hambly and Hambly 1994): This is a brainstorming approach, where the use of only some specific words is allowed in order to infer limits and detect risks. The most significant application domain is chemistry. There are also some automated risk identification approaches (e.g. using loT) as presented in (Gao et al. 2020).

Cost Benefit Analysis and Risk Benefit Analysis (CBA and RBA) (1986): These very commonly accepted approaches are based on composing a balance sheet of costs versus benefits.

Sensitive Analysis (SA) (Covello 1987): This method provides an evaluation of the robustness of the system by performing the quest of "what if" scenarios.

Hertz-type simulation (Ho and Pike 1992): This approach generates a probability distribution by simulation of the various combinations. 
Monte Carlo (Covello and Merkhofer 1993): The well-known Monte Carlo approach can be significant in the context of risk management to reduce the variance of probability.

Expert Systems (Kletz 1990): The well-known expert systems can be used in the context of risk management to infer causal chains.

Finally, as stated in (White 1995), all these approaches can be connected to the different risk management phases presented on Figure 2:

From these results, the most obvious statements are that (i) the monitoring phase of risk management is not considered by the presented methods, and (ii) the mitigation phase seems not to be satisfyingly addressed. Basically, this means that that the second half of the risk management cycle is almost not covered. It is quite a logical statement due to the fact that identification and assessment are the phases dedicated to preparing the material for decision makers to take their decisions. Mitigation (and moreover monitoring) has always been considered more like a human only activity. As a conclusion, this study shows that there are plenty of (manual) tools and approach to perform the first step (risk and opportunity identification and modelling) of the vision presented in this article. However, there is no strict contribution to perform it from an automated and data science point of view.

\subsubsection{Contributions from Management Science}

In Management Science, there are several well-recognised (even if not systematically wellappreciated) strategic tools and approaches that should be considered in the context of

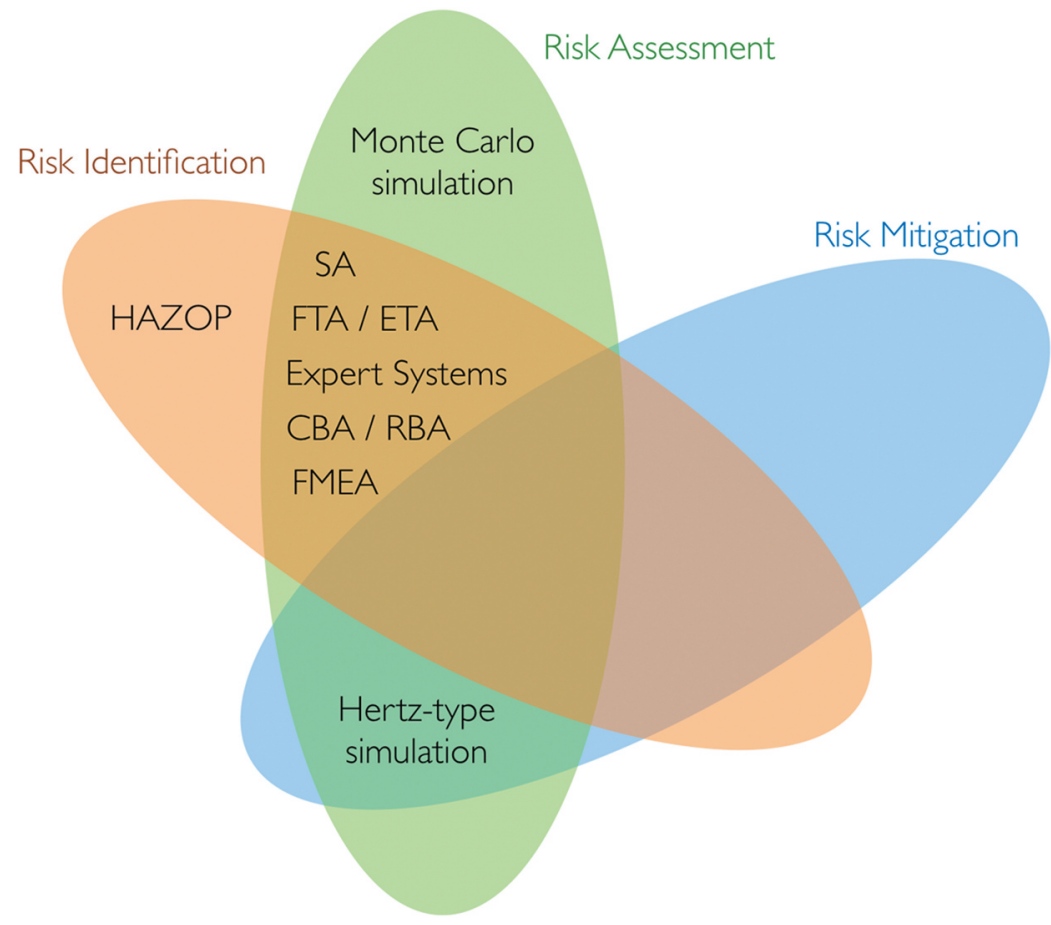

Figure 2. Risk management techniques versus phases of risk management process. 
this article. The following analysis tools can be specifically identified: SWOT, Scenario Planning, Value Chain, Porter's five forces, PEST and PESTEL. To give a rough idea of the level of adoption of these tools among organisations, (Gunn and Williams 2007) studied their usage within a large number of organisations (public and private). This study is focalised on a particular economic area of the UK, and it shows the following Figures: $70 \%$ of these organisations claim that they have already used a SWOT analysis, $28 \%$ of these organisations have used scenario planning, $20 \%$ of these organisations have used value chain analysis, and finally, $13 \%$ of the same organisations have already used Porter's five forces.

The SWOT analysis (or SVOR in the domain of project management) stands for Strengths, Weaknesses, Opportunities, and Threats (respectively Strengths, Vulnerabilities, Opportunities, and Risks). This approach is fundamental and has first been introduced by the Harvard Business School (approximately in the 50s-60s). It classifies positive/negative and external/internal potentialities, and is classically presented as follows in Figure 3:

(Dietz, Proper, and Tribolet 2009-2014) describes the SWOT Analysis as principally dedicated to the identification of (i) the characteristics of the observed system (so called Strengths and Weaknesses) and (ii) the characteristics of the context of the considered system that the system is susceptible to (so called Opportunities and Threats).

(Dietz, et al., 2009) compares the SWOT analysis on the one hand, and the TELESCOPIC (specifically introduced in that paper) on the other hand. TELESCOPIC is very comparable to the PEST analysis. Actually, there are a lot of approaches very close or similar to the PEST analysis. Historically, the PEST analysis has been first introduced at Harvard by Aguilar in the 1960s and then improved by several authors (like Brown or Davenport) to create the STEP, PESTE, PESTEL approaches (or the aforementioned TELESCOPIC analysis).

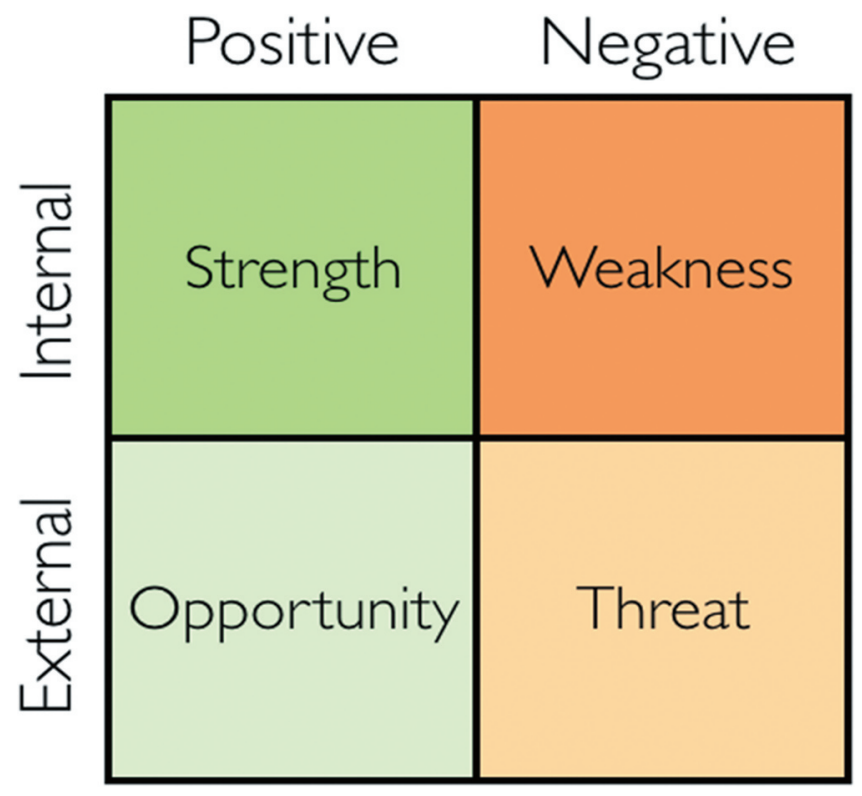

Figure 3. Classical SWOT matrix. 
These different approaches are based on a mnemonic dedicated to list all sectors that one should take into account as potential sources of risks. For instance, for PESTEL as presented in Figure 4: P stands for Political, E for Economic, S for Social, T for Technological, E for Environmental, and L for Legal.

One complementary link between SWOT analysis and PESTEL analysis is that the identification of Opportunities and Threats from SWOT (or Opportunities and Risks from SVOR) can be performed by exploring the sectors of the PESTEL framework.

Again, as a conclusion of that subsection, it is easy to see that there are plenty of manual approaches and tools for risk and opportunity identification and modelling (first step of the vision presented in this article). However, (i) there is no direct automated implementation of these approaches, and (ii) no tangible contribution for the second step (trajectory control).

\subsection{A Theoretical Framework for Data Management}

This second subsection aims at delivering, through a dedicated literature review, a vision of a decision-support framework, in which the innovative management of risks and opportunities can be performed. The starting point is to consider that the decisionmaking process is a climb in abstraction layers from raw data to decision.

\subsubsection{A framework for data, information, decision and knowledge}

During the last decades, the precise visions and definitions of the concepts of data, information and knowledge have been deeply examined. The DIK (or DIKW) hierarchy, ${ }^{4}$ (Data/Information/Knowledge/Wisdom often presented as a pyramid and described in (Rowley 2007)), inherited from decades of thoughts in philosophy, information sciences, technology and more generally broader science, is at the root of these visions and definitions: in layman's terms, if ' $1.65 \mathrm{~m}$ ' is a measure, this is a piece of data, if we know

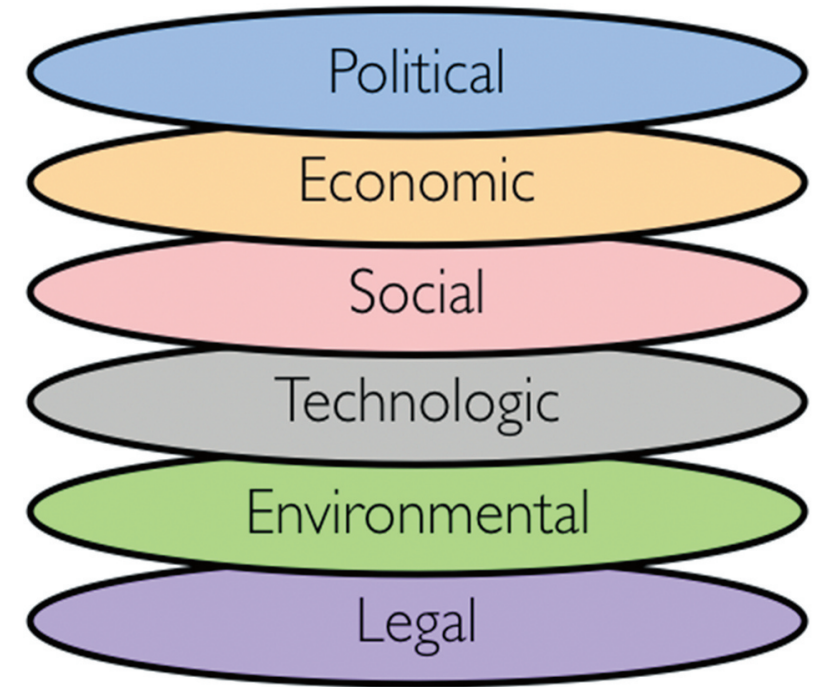

Figure 4. The PESTEL sectors. 
that ' $1.65 \mathrm{~m}$ is the height of Mr. Smith', this is an information, and assuming that ' $1.70 \mathrm{~m}$ is the average height of the population to which Mr. Smith belongs, $1.65 \mathrm{~m}$ is rather small height' is knowledge. In (Ackoff 1989), one can find the following significant definitions: 'Data are symbols that represent properties of objects, events and their environments. They are products of observation', 'information is referred from data, it is contained in descriptions, answers to questions that begin with such words as who, what, where, when and how many' and, 'Knowledge is conveyed by instructions, answers to how-to questions'.

Some interesting and more recent definitions can also be found in, (Rus and Lindvall 2002): 'Data consists of discrete, objective facts about events but nothing about its own importance or relevance; it is raw material for creating information' while 'Information is data that is organized to make it useful for end users who perform tasks and make decisions' and 'Knowledge is broader than data and information and requires understanding of information (information about information, such as who has created the information).'

In (Tolk 2005), the concept of common operational picture, which basically has first been defined in the field of command and control (see (Dickinson 2013)), is depicted as requiring the contextualisation of data to generate information. The generated information, saved as models, is then analysed, updated and monitored to support decision.

Basically, there are four main notions to consider in order to organise the exploitation of data: data, information, decision and knowledge. Based on the previous considerations, this article refers to the following definitions:

Data: formalized observation of the world.

Information: result of the interpretation of data through the instantiation of conceptual references.

Knowledge: capitalized static information about previous experience or extracted abstract concepts.

Decision: choice, conclusion or judgement made after processing actionable information and knowledge about the situation.

For instance, let us consider the following example of data: 'wild fire', 'city', and 'wind'. This dataset can be interpreted through sense-making mechanisms to create the following information: 'there is a wild fire close to a city where there is wind', which may provide the following information 'there is a threat on the city' which is a risk, or at least a potentiality. Analysing and processing this information may support the decision of 'triggering the evacuation of the city'. This decision is also based on knowledge such as the concept of what is a 'risk' (or a 'potentiality') and stored instances about the fact that 'the wind is a strong factor for the fire to spread'.

This paper lies on a quite strong hypothesis about data. Actually, there are absolutely no questions of trust, source discovery, cleaning of data, redundancy management, understanding. The position of this paper is to deal with supposedly available data that are meaningful and trustable.

The resulting K-DID (Knowledge/Data/Information/Decision) Framework, directly referring to the DIKW hierarchy introduced earlier, is presented on Figure 5. The choice of considering Decision results from a different point of view than the DIKW hierarchy. 
Instead of considering an abstraction hierarchy of piece of data (interpreted, contextualised, stored, etc.), the K-DID framework aims at describing the decision process: how, from the gathered data, then interpreted and contextualised can the appropriate decision be taken.

\subsubsection{A framework combining Data Science and Industrial Engineering}

Both Data Science and Industrial Engineering aim at supporting the decision-making process. Both aim at providing organisations with approaches and tools to manage efficiently their activities, with regards to internal and external events. To reach that objective, Data Science is mainly based on Data Analytics (Gandomi and Haider 2015) to work on dashboard, while Industrial Engineering basically focuses on Enterprise Modelling (Vernadat 1996) to reason on situations.

As for Data Science, (Jagadish et al. 2014) describes two main parts: Data Management and Data Analytics. Data Management includes Acquisition, Content Extraction and Data Integration and Representation. Data Analytics includes Analysis and HumanInterpretation. It is easy to draw the line between this vision of Data Science and the KDID framework on Figure 5. Data Management fills in the data layer while Data Analytics aims at providing the user with visualisation that may be interpreted by him. Actually, the Analysis stage of Data Analytics is dedicated to performing detection of frequent patterns and correlations to obtain general statistics, which is basically what is expected at the decision layer of Figure 5.

As for Industrial Engineering, two main parts may be identified as well: Enterprise Modelling and Model Driven Engineering. From (Vernadat 2002) Enterprise Modelling can

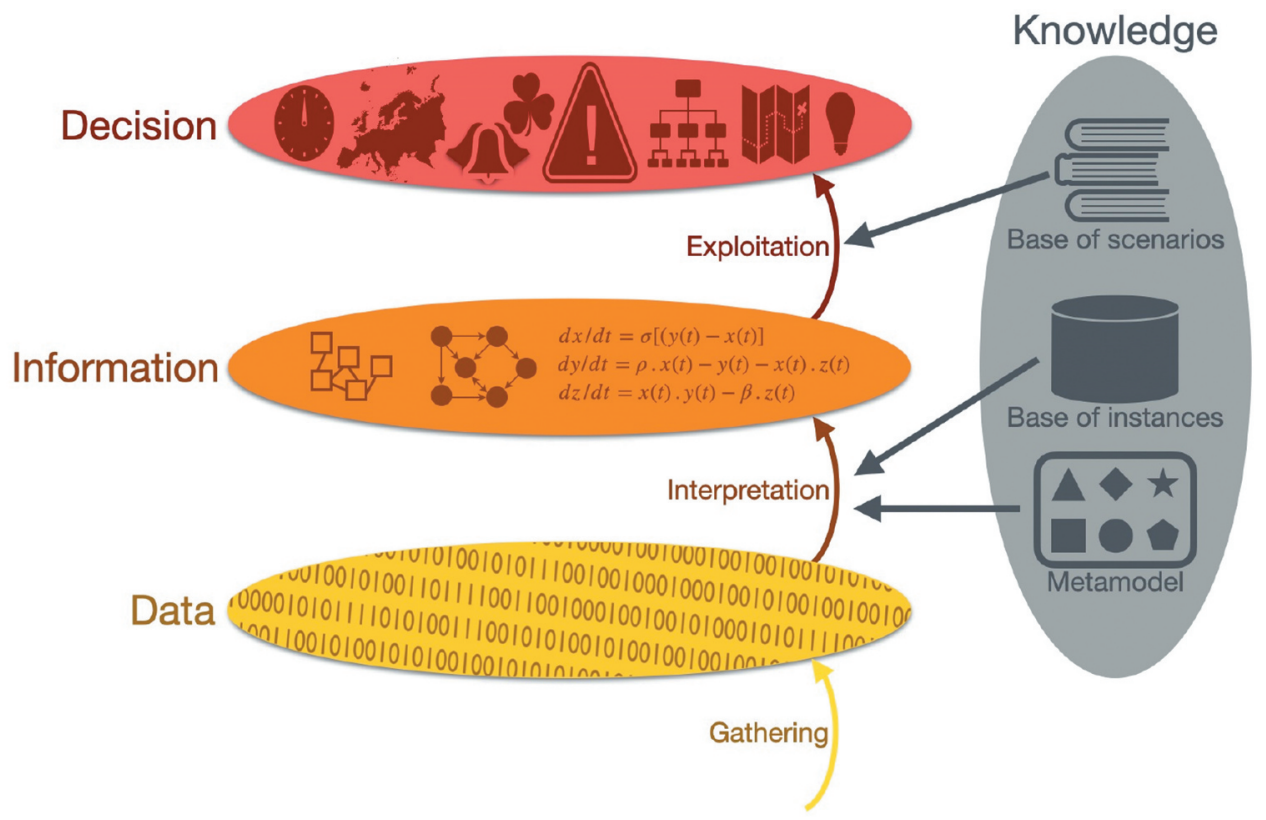

Figure 5. The K-DID framework presenting the abstraction levels data, information, decision and knowledge. $^{5}$ 
be considered as mainly using expert modellers to create (based on dedicated approaches and associated metamodels, know-how and knowledge basis) models that can then be exploited for decision support. It also provides a support for knowledge management. Model Driven Engineering as studied in (Rodrigez da Silva 2015) and described more precisely in the context of industrial engineering (and not software engineering) in (Dietz, et al., 2009) considers that models might be used throughout all engineering disciplines and in any application domain, through model transformation, metamodel conformance, etc.

Consequently, the following picture illustrates how Data Science and Industrial Engineering can be located on the K-DID framework. The upper left part of Figure 6. concerns Data Science (Data Analytics and Data Management), the upper right part concerns Industrial Engineering (Enterprise Modelling and Model Driven Engineering).

There are plenty of definitions of intelligence. Most of them include several features: (i) understanding, (ii) deciding or acting, (iii) adaptation to circumstances and objectives, (iv) based on knowledge, (v) abstract and formal. In the context of this article, and based on the previous element, we will consider the following definition of intelligence: The capacity to use one's senses to understand any given situation and enact accordingly to reach one's objectives. This definition includes all the features previously mentioned and could be used to define Data Science and Industrial Engineering according to the bottom part of Figure 6:

Data science: Use one's senses to enact to reach one's objectives (missing the situation understanding part).
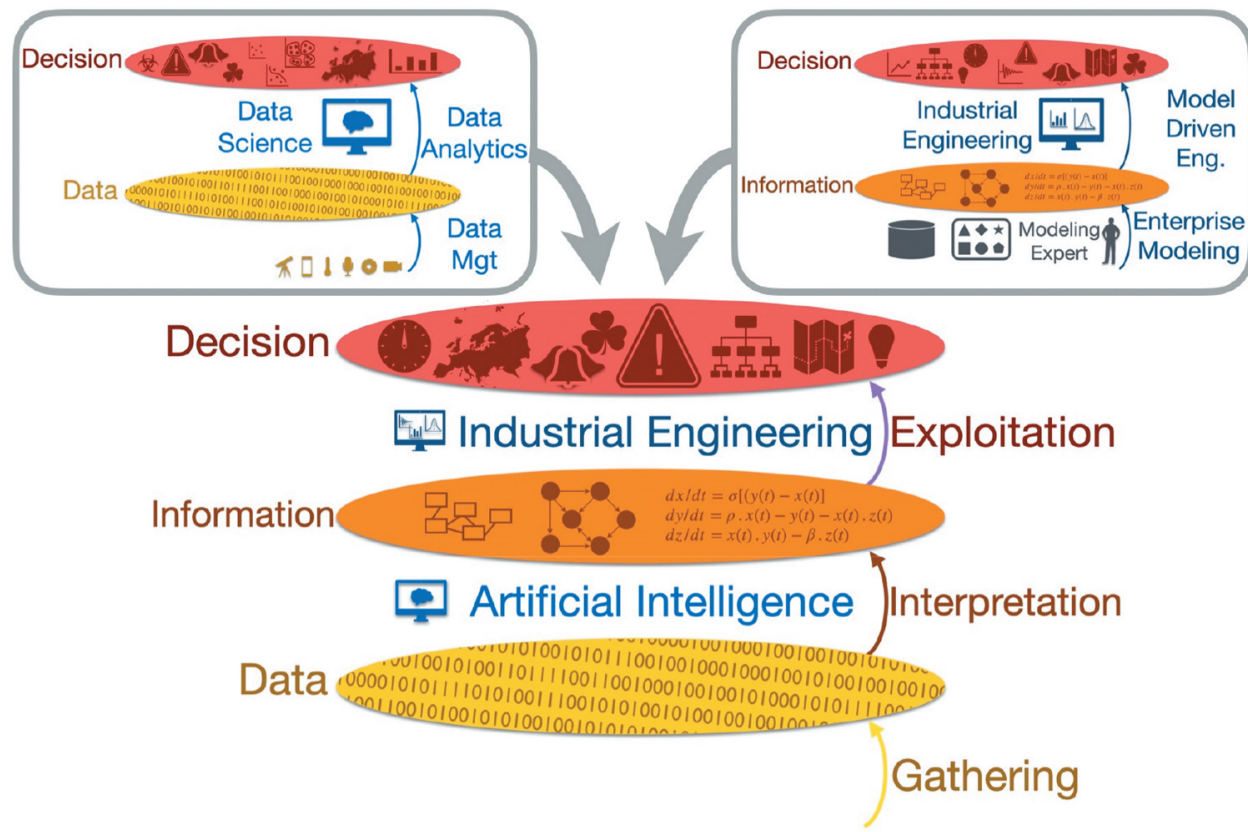

Figure 6. The location of Data Science (upper left) and Industrial Engineering (upper right) on the K-DID framework. 
Industrial Engineering: Analyze any given situation to enact accordingly to reach one's objectives (missing the sense-based collection part).

Both these visions show how partially Data Science and Industrial Engineering contribute to provide artificial intelligence for decision support. As a consequence, and in continuity with previous work (Benaben, et al., 2019b) the ambition is to use Data Analytics to build situation models and to use Model Driven Engineering to use the obtained models for decision support. The following Figure 7 illustrates this Al framework mixing Data Science and Industrial Engineering:

This framework can easily be connected to the considerations of section 2.1 about risk and opportunity management: the two first stage of risk management (risk and opportunity detection and modelling) can be located as the 'data to information' transition of Figure 7 while the two last steps (decision making for trajectory control) can be located as the 'information to decision' transition on Figure 7.

\subsection{Conclusion about the studied contributions}

No matter the considered techniques or approaches presented in the previous subsection 2.1, they are massively dedicated to the first step of risk identification and assessment (grouping the two first phases). However, almost none of them is able to contribute to the second identified level, i.e. the decision-making process (grouping the third and fourth phases of the risk management cycle). The challenge is consequently to exploit the existing contributions to achieve the first step and to provide some innovative contribution(s) to achieve the second step. Besides, some of these approaches are dedicated to understand the observed system and its environment (e.g. PESTEL), some others are dedicated to identify existing options (e.g. Hertz-type), and very few allow to

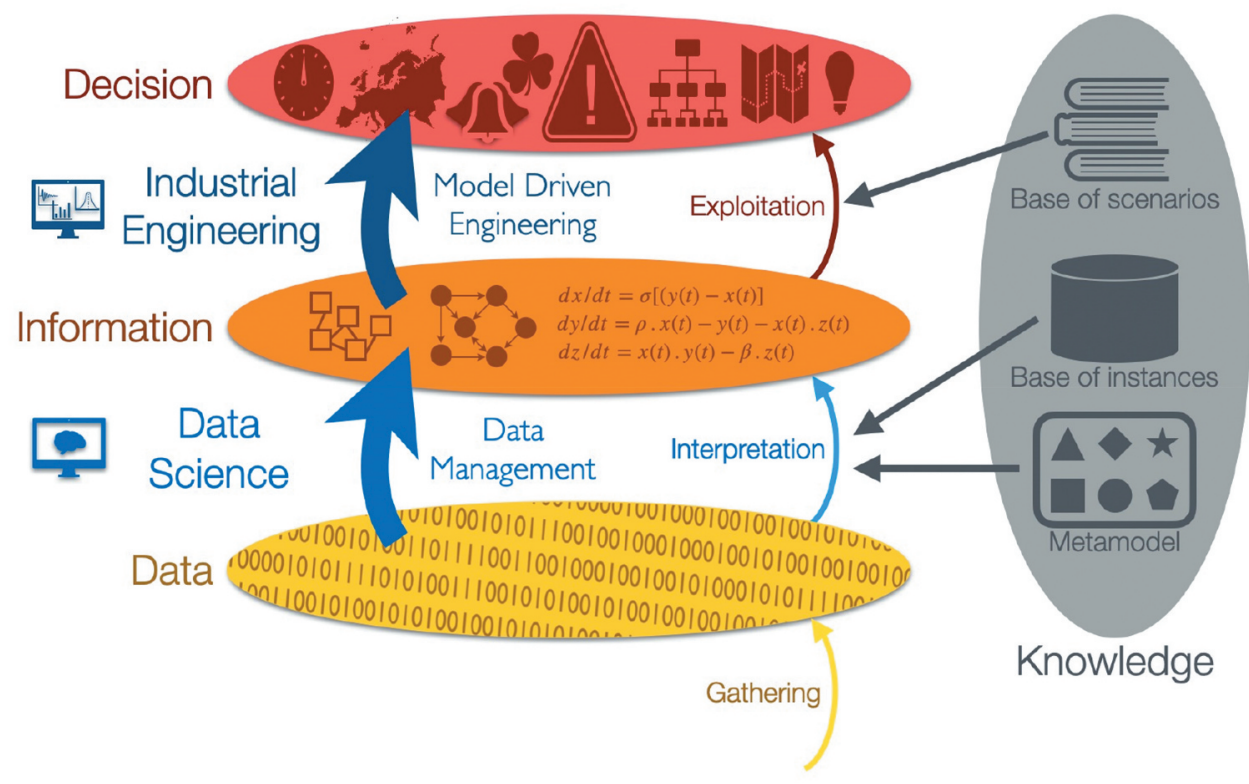

Figure 7. The Artificial Intelligence framework, based on the K-DID one. 
choose among options (e.g. multi-criteria decision-making). It is so relevant to consider the decision-making process as a whole ambition and to define a dedicated framework of modelling. The theoretical framework resulting from the study of section 2.2 and presented on Figure 7 can be considered as a general framework for decision-making. This paper claims that this framework can be used for its dynamic part (i.e. the climb in abstraction to reach the decision level), considering that this dynamic part of this framework concerns the way to use inputs (data?) about the observed situation (and system) in order to (i) formally model the considered system and the faced situation (especially the risks and opportunities), and (ii) exploit these models to support the process of decisionmaking with regards to the target objectives, and the identified and modelled risks and opportunities. The next section presents the proposed approach for decision-making through performance management within this theoretical framework.

\section{A Physics-based risk and opportunity management framework}

In this section, the general vision is presented according to two subsections. The first one introduces the causal, propagation and decision chains as the fundamental basis of the vision. The second one introduces the modelling frameworks as an implementation environment. The presented physics-based theory is not related to the use of equations that would formally describe the behaviour of the system within its decisional context. However, the term 'physics-based' is due to the fact that risks and opportunities ae seen as physical forces changing the performance of the system by deviating its trajectory within the framework of its KPI dimensions.

\subsection{The causal, propagation and decision chains}

In (Zeng and Yen 2017) the notion of risk is modelled according to three related concepts: (i) the concept of danger (or driver) that creates the risk on a system (susceptible to the danger), (ii) the concept of event (or condition) that carries the probability of the risk occurrence, and (iii) the concept of consequences that shows the expected effect of the risk occurrence. A very close point of view has been introduced in (Benaben et al. 2014) and ( $\mathrm{Li}$ et al. 2018) to present the causal chain: danger - risk - consequence. That causal chain is mainly negative and can be extended and generalised to a more neutral perspective, as it is described in (Benaben, et al., 2019b), to the concepts of characteristic (favourable condition or danger) - potentiality (opportunity or risk) - actuality (benefit or damage). This generic causal chain is presented with the blue concepts on Figure 8:

One clear inspiration of this extended causal chain is the notion of force fields creating forces that impact susceptible systems and make them potentially move. The yellow concepts of Figure 8 present that inspiration. It is also important to notice that this vision still remains well-suited with the traditional modelling of risks, presented in section 2.1: Actually, the idea of probability of risks is embedded into the probability of the condition to be true. The effect (impact or benefit) of risks is eventually embedded in the concept of actuality. For instance, a SME-type company (system) may be susceptible to a potential new law about tax rate for company of less than 200 employees (characteristic), which could create a $20 \%$ reduction (potentiality). But this should be approved by a decisional executive assembly (condition) to concretely create that benefit for the company (actuality). 


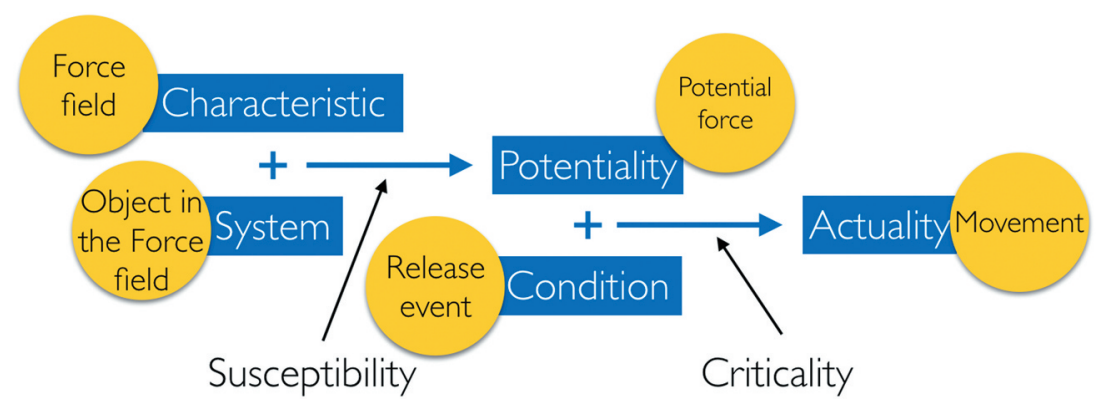

Figure 8. The extended causal chain model.

Furthermore, it is also possible to connect this model with all the Management Science techniques introduced in subsections 2.2 and 2.3. Actually, these approaches can be used specifically to identify and characterise the characteristics and potentialities of the causal chain presented on Figure 8. Particularly, the approaches of subsection 2.2 can help to identify and characterise the potentialities that can be disseminated in the SWOT matrix, while specifically the PESTEL approach can be used to identify and characterise the characteristics of the observed system. The PESTEL framework can also be used to structure the potentialities identified in the SWOT Matrix (with the approaches of subsection 2.2). Figure 9 presents these principles and the connections between the model of the current article and the results from the literature review in the domain of Management Science:

Moreover, considering that such a chain actually produces potentiality (from characteristic and system) and actuality (from potentiality and condition), it is important to notice that both these elements (potentiality and actuality) are the emerging ones. Besides, these elements can perturbate existing elements. For instance, an actuality can create, modify or remove an existing system (e.g. a lower tax rate can reinforce the investment capacity of a company). It can also create the condition for another causal chain (e.g. an actual new contract with a new 'big player' customer can trigger the contract with a supplier). So, basically there is thus a propagation chain (as presented in red in Figure 10) that shows how potentiality and actuality can create, modify or remove existing characteristics, systems or conditions of (other) causal chains:

Finally, considering that the actuality is the tangible consequence of the risk or opportunity, it is legitimate to consider that this is on the basis of this actuality that the evolution of the performance of the system should be assessed. Basically, the impact of the actuality (changes of the KPIs) should be compared to actual objectives to diagnose if the 'trajectory' is relevant. As for this notion of 'performance objective', within the context of the vision presented in this article, it is basically considered as a set of target values of the predefined KPIs. These target values could be of various forms, like absolute values (e.g. $\mathrm{t}=3 \mathrm{~ms}$ ), [min, max] intervals (e.g. $2.8 \mathrm{~ms} \leq \mathrm{t} \leq 3.2 \mathrm{~ms}$ ), or even more complex values (e.g. fuzzy values, functions, etc.).

Moreover, symmetrically to the fact that potentiality and actuality are the pro-duced elements (as mentioned to explain the propagation chain), characteristic, system and condition are the input elements. This means that these elements contain the space of decision, i.e. they are the elements that can potentially be changed to control the situation. In other words, the decision space is a sub-space of all 


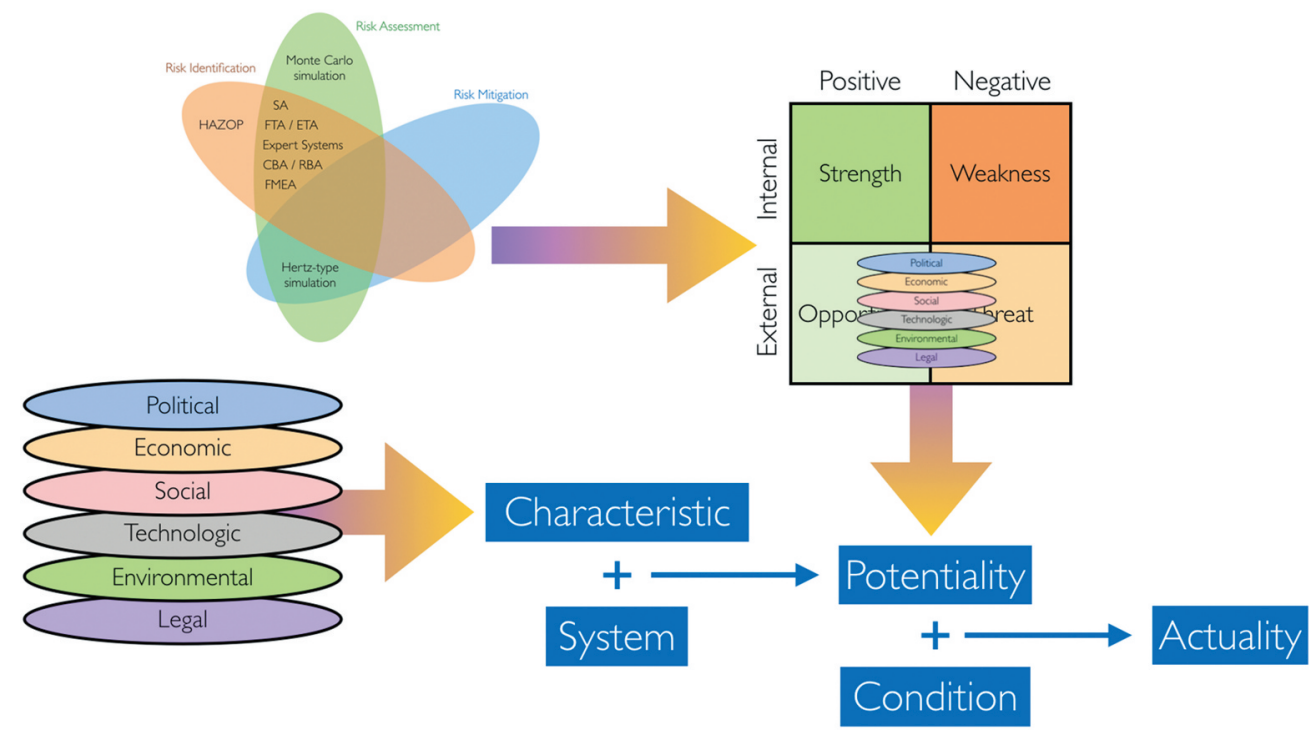

Figure 9. The potentiality causal chain and existing contributions.

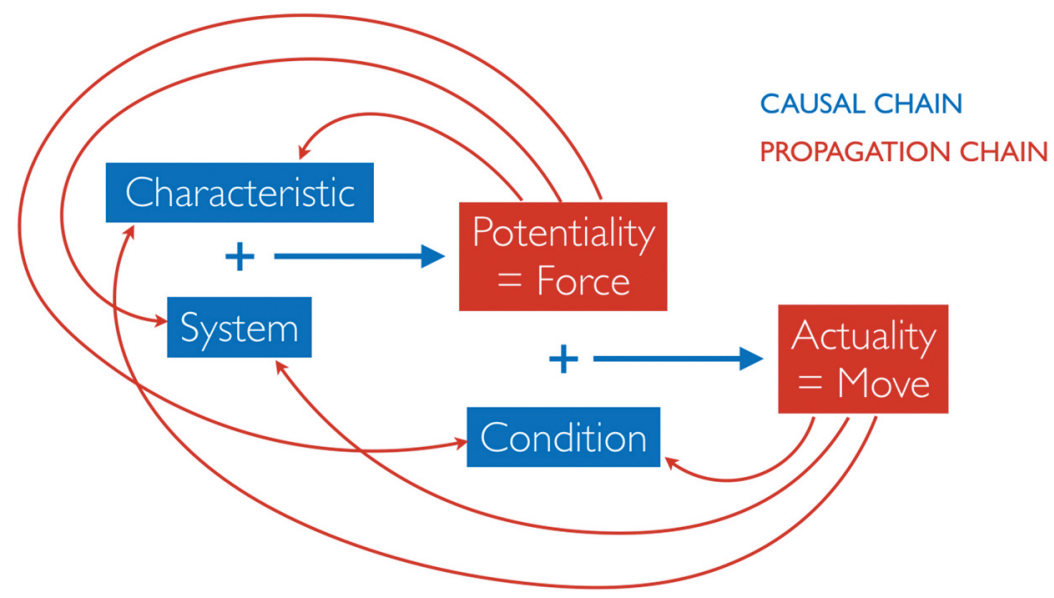

Figure 10. The propagation chain model.

characteristics, systems and conditions (sub space because some of these can not be controlled).

Figure 11 illustrates on the one hand the link between objective assessment and movement, and on the other hand the decision applied on characteristic, system and condition. These connections represent the decision chain.

On the basis of this framework inspired from the notion of potential forces in mechanics, the very promising aspect is that would we be able to interpret data to first, identify and model the characteristics of the considered system's context, and second, to define the susceptibility of the system to these particular characteristics, then the forces exerted on the system could be determined and strictly defined. 


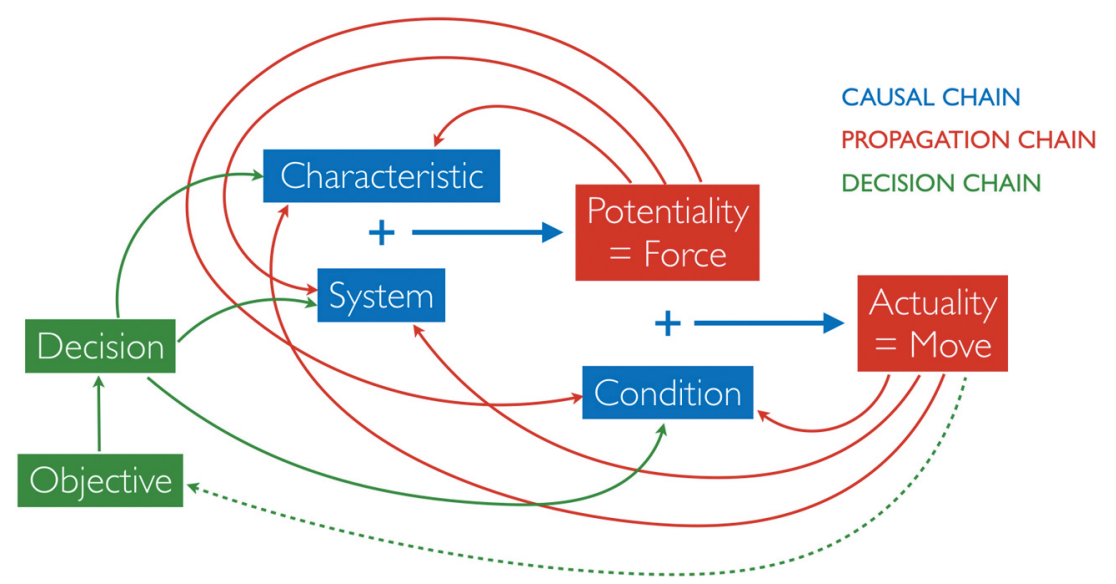

Figure 11. The decision chain model.

\subsection{Two connected modelling frameworks}

Based on the aforementioned elements, the overall idea is to see the 'Physics of Organization Dynamics' as requiring two different modelling environments: the 'susceptibility framework' and the 'performance framework'. The susceptibility framework it is dedicated to characterising systems and their environment. The main principle of this first description framework is to position components of an observed situation within dimensions that represent the exact nature of the system. For instance, it can be geography (like latitude, longitude, altitude), dependency (nature of inputs or outputs, energy type), type (domain, sectors, weights, size), social or legal status, image, communication, reputation, etc. Obviously, this is just an open set of dimensions, which can be enhanced with any further dimensions significant to any specific context. One benefit of locating the system within such a susceptibility framework is that all characteristics of the environment (favourable conditions, dangers, and all type of impactful characteristics) may be modelled as a Boolean value in this modelling space. Basically, it means that for any point in the susceptibility framework, the modelled characteristics concerns (1) or not (0) all the systems located in that specific point. For illustration purpose, let us take two examples: a project of tax reduction in the European laws (a local characteristic), specifically dedicated to companies of maximum 250 employees (considered systems) would specifically and directly impact SMEs officially based in Europe. Similarly, the huge danger of earthquake in Japan (which is a characteristic) would specifically directly impact organisations of any type (which are considered as systems) with geographical location in Japan. Clearly, the number of these significant dimensions should change depending on the considered context and use-case. Figure 12 presents this idea of susceptibility framework in an illustrative case where the considered systems are companies and the dimensions are only coordinates and size of these companies.

As a complement, characteristics could be represented not only as a Boolean function, but using a more refined function (for instance, it might be a general distribution from 0 to 1 based on the effect, or even from -1 to 1 if we want to carry the risk/opportunity 


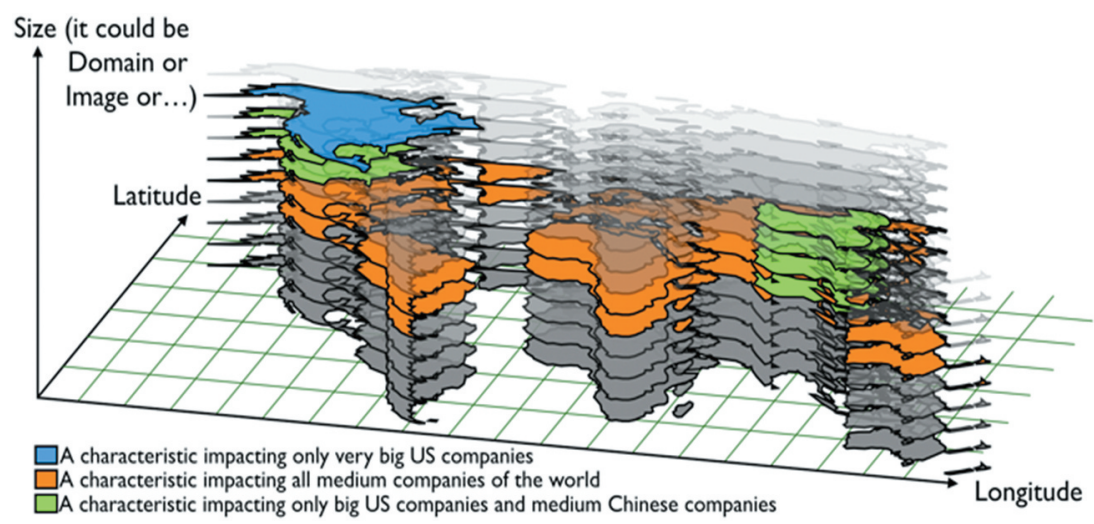

Figure 12. An illustration of susceptibility framework with coordinates and size of companies as dimensions.

meaning). Nevertheless, for the purpose of this explanation and illustration, a Boolean function is considered as meaningful enough as it will be shown in the following.

Another important remark concerns the fact that, in addition to systems and characteristics, the susceptibility framework can also be used to express conditions (in the meaning of the causal chain). Actually, a condition can be expressed within the dimensions of the susceptibility framework.

The second modelling space is the 'performance framework'. It is dedicated to observe the general and detailed performance of the considered system by representing the impact of the modelled characteristics on the performance of this systems as (actual/ potential) moves due to (actual/potential) forces: This performance framework aims at positioning systems with regard to the dimensions of their KPIs and also to show, as force vectors, the effects of the characteristics modelled in the susceptibility framework (as moves of the systems, with regards to these KPIs dimensions). The important benefit of having this second modelling space, is that this is the framework where the trajectory of systems (representing the continuous evolution of the performance location) can be represented and analysed. Figure 13 presents this performance framework.

On Figure 13, one can see that the system (represented as the red sphere) in its 3D KPI framework, the risks and opportunities seen as forces (coloured vectors), the target zone of the framework and another zone that is actually easier to reach due to the forces.

Regarding the Theoretical framework introduced in section 1 (see Figure 3.), the information layer is supported by the susceptibility framework, while the decision layer is supported by the performance framework.

The overall approach presented in this section describes a theoretical framework dedicated to formally support decision-making by allowing the modelling and description of risks and opportunities (i.e. potentialities). These potentialities are seen as physical forces, inflicted on the considered systems, and assessed according to their consequences on the performances of these systems. The main contribution of this paper is therefore to deliver a theoretical vision to deal with uncertainty (and instability). 


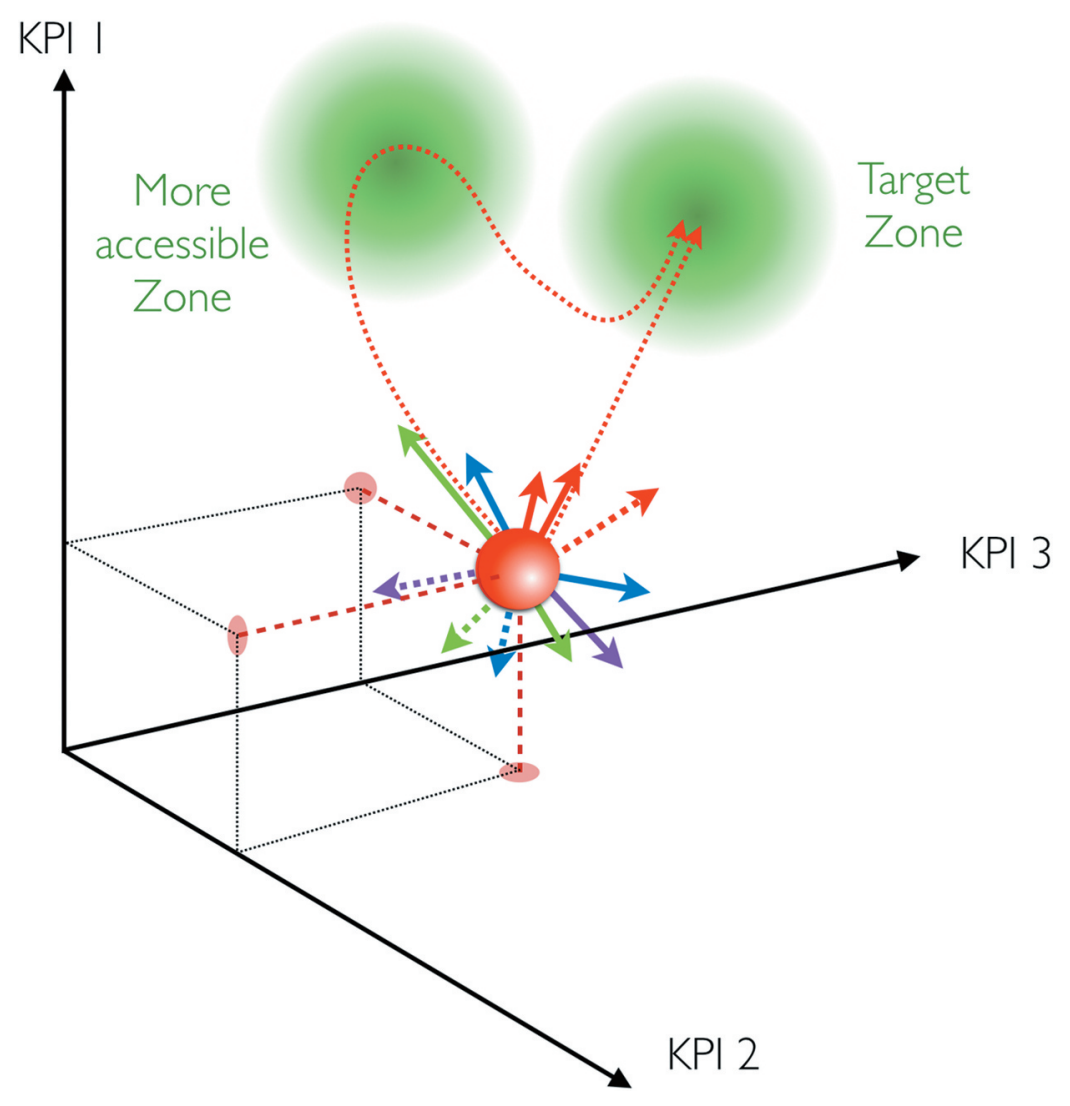

Figure 13. The performance framework.

\section{Illustration with a simple use-case}

Nota Bene: This scenario is completely fictional and is not dedicated to be realistic at all. This is just a use-case to illustrate the previous considerations and make them more understandable. Besides, this use-case is not a 'demonstrative' use-case (which would be dedicated to make the proof of the real usage of the approach with a high level of readiness), but typically a 'pedagogical' use-case (which is dedicated to clarify principles, paradigms and concepts potentially abstract and hard to apprehend through applied illustration).

Let us start with the case of a power plant dedicated to provide electricity to a midtown, a neighbourhood, and an hospital of its territory. In addition to producing electricity, the plant is also in charge of the dispatching of energy. In that purpose, the thermal plant stores electricity that it produces and buys electricity from two other electricity suppliers: a hydroelectric dam and a nuclear plant. Figure 14 presents this situation:

Fundamentally, all components of the considered situation can be susceptible to any contextual characteristics. For example, there might be weather events (e.g. a drought) that might impact directly some of the components. Actually, if the components are in the zone of the weather event, and if they also are susceptible to 


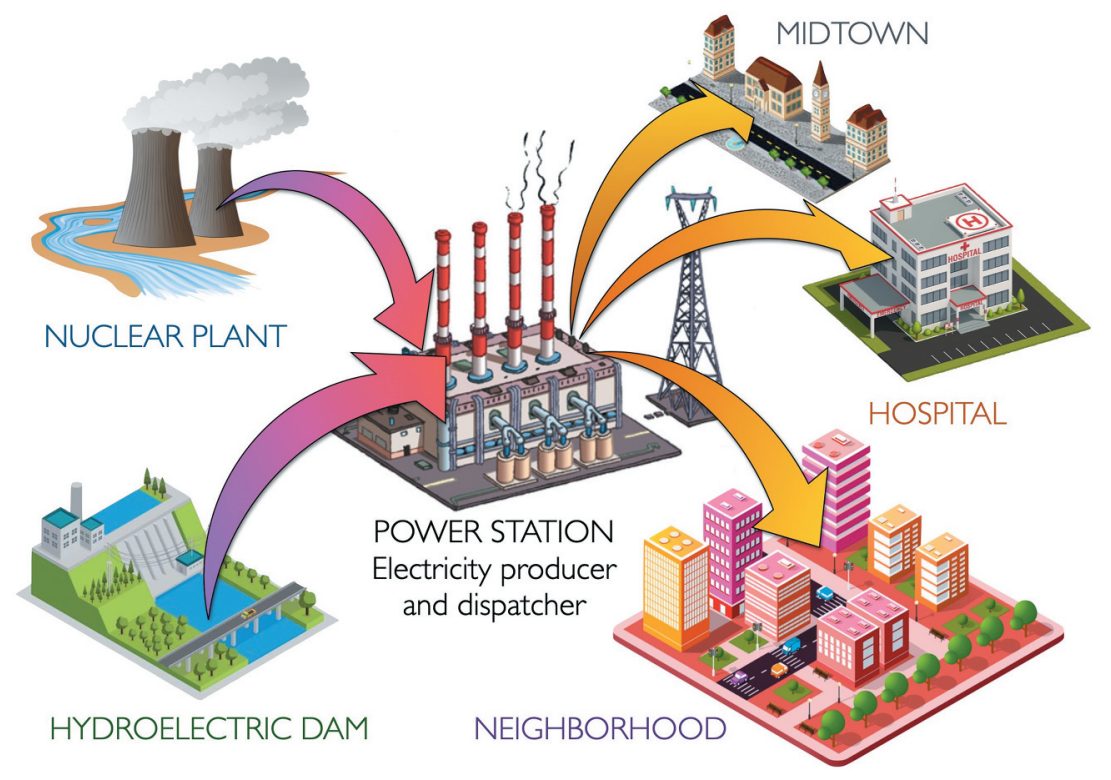

Figure 14. The energetic network of the fictional scenario.

this event, there might be some consequences. For instance, the hydroelectric dam might have to significantly reduce its production of electricity in case of severe drought. On another perspective, a change on the coal market might have effects on the components that depend on coal: for instance, the thermal power plant might be significantly impacted on a financial dimension by variations of the coal price. On another point of view and due to the green consciousness, there may be some civic and social activists that could disturb the activities of both the power station and the nuclear plant. The consequences could potentially be drastic reduction of their production of electricity.

This general principle of susceptibility of the identified and modelled components to some contextual characteristics, depending on their nature, their inputs/outputs, and their geo-location illustrates the principle of the susceptibility framework. Figure 15. describes that susceptibility principle with regards to the considered use-case by presenting the associated susceptibility framework.

The key benefit of the notion of susceptibility is that it allows to describe how each characteristic might impact the performances of each considered components. The question is the following: assuming that it is possible to locate each component with regards to its own KPIs, what will be the concrete effects of a considered character-istic, to whom the component is susceptible, on that precise location? This paper suggests answering to that question by modelling this impact according to two terms:

a relative term (depending on the current location of the component in its performance framework), for instance "there will be a loss of $10 \%$ of the profit" (where the profit is a KPI), and, 


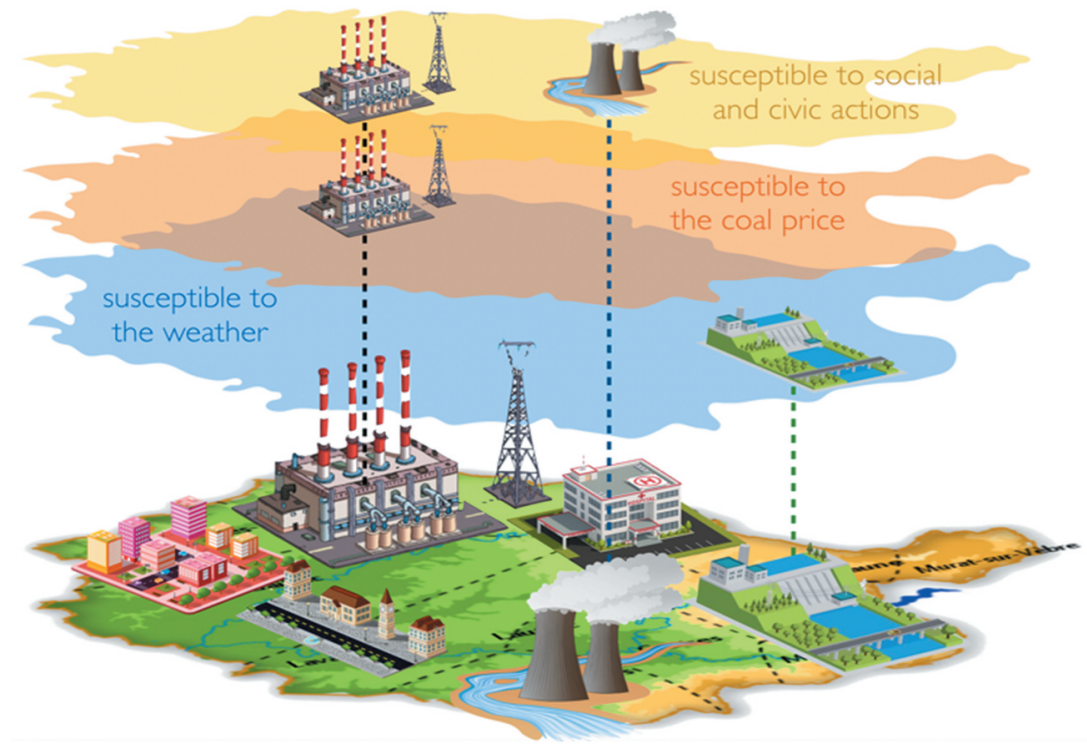

Figure 15. The susceptibility framework representing how components of the considered systems are susceptible to some contextual characteristics.

an absolute term (independent from that same location), for instance "there will be a loss of $100 \mathrm{k} €$ in the profit, whatever the actual value of the profit".

On a modelling point of view, this vision can be described with the following structure:

A component $C$ can be characterized according to $N$ dimensions: $C=\left(c_{1}, c_{2}, \ldots c_{n}\right)$ such as longitude, latitude, type, nature, size, type of inputs, type of outputs, etc.

A characteristic of the environment is a Boolean function of occupation of the same $\mathrm{N}$ dimensions: $C h\left(x_{1}, x_{2}, \ldots x_{n}\right)=1$ if the characteristic $C h$ is actually present in the location $\left(x_{1}\right.$, $\left.x_{2}, \ldots x_{n}\right)$. Else, $C h\left(x_{1}, x_{2}, \ldots x_{n}\right)=0$.

The location of $\mathrm{C}$ in these $\mathrm{N}$ dimensions determines its susceptibility to characteristics: At instant $t, C$ is susceptible to all characteristics that have a non-null value at the coordinates of $C$ at instant $t$.

If $C$ is susceptible to a characteristic $C h$, then there is a matrix $M_{C h}$ and a vector $V_{C h}$ that represent respectively the relative term and the absolute term of the impact of the characteristic $\mathrm{Ch}$ on $\mathrm{C}$. Then the force of $\mathrm{Ch}$ on $\mathrm{C}$ is: Force $=\mathrm{M}_{\mathrm{Ch}} \cdot \mathrm{C}+\mathrm{V}_{\mathrm{Ch}}$.

$M_{C h}$ is a MxM matrix (impact matrix) and $V_{C h}$ is a vector (impact vector) of $M$ terms (where $M$ is the number of KPIs considered for $C$ ). If the $M$ KPIs are independent, then $M_{C h}$ is a diagonal matrix.

$$
\text { Force }=\left[\begin{array}{ccc}
m 1,1 & \cdots & 0 \\
\ddots & \cdots & \ddots \\
0 & \cdots & m m, m
\end{array}\right] . C+\left[\begin{array}{r}
V 1 \\
\ddots \\
V m
\end{array}\right]
$$

Obviously, there are good chances that the KPIs might not be independent and that the matrix $M_{C h}$ would not be a diagonal matrix. However, there is also good chance that, 
depending on the type and nature of the faced events or characteristics, matrix and vectors could be based on different profiles. This idea implies that there could be some laws describing the impact of some characteristics on systems (probably depending on both the nature of the characteristic and the attributes of the susceptible system). It is not unreasonable to think that the impact of a weather event or economic reform, insofar as they involve relatively predictable micro-consequences, is ultimately fairly stable in its form and dependence on external parameters.

Let us know consider a very basic performance framework composed with two KPIs: money and capacity. Based the susceptibilities described on Figure 15, a net of forces can be identified for the Power Station. There are actual forces (represented with solid arrows) and risk or opportunities, i.e. potential forces (represented with dash arrows).

On the following Figure 16 it is noticeable that, on the one hand buying electricity obviously decreases the money level and increase the capacity, while, on the other hand, selling electricity, decrease the capacity but increase the money indicator. In the observed system, the net of forces is exactly balanced (globally and also specifically in the money and capacity dimensions) as shown on Figure 17.

If we now consider a weather problem (for example a drought), this specific event can update the net of force vectors in the performance space. Actually, in this specific situation (drought), the hydroelectric dam is not able to generate electricity anymore because the water should be preserved in the dam. Specifically, the purple solid arrow representing the purchase of electricity to the hydroelectric dam on Figure 16 is changed into the purple dash arrow due to the drought. Consequently, there is a global force pulling the performance of the power station left and up: the observed system will move as presented of Figure 18 with the red blurry circles.

Actually, this result is obviously normal and easy to interpret: the customers will still go on purchasing electricity (which brings an unchanged amount of incoming money flow) but the power station will reduce its purchase of electricity (which brings a reduced amount of outgoing flow of money). This phenomenon is presented on Figure 19.

Roughly speaking, the observed situation basically shows the transformation of stored electricity in money. Obviously, the obtained up and left trajectory cannot be

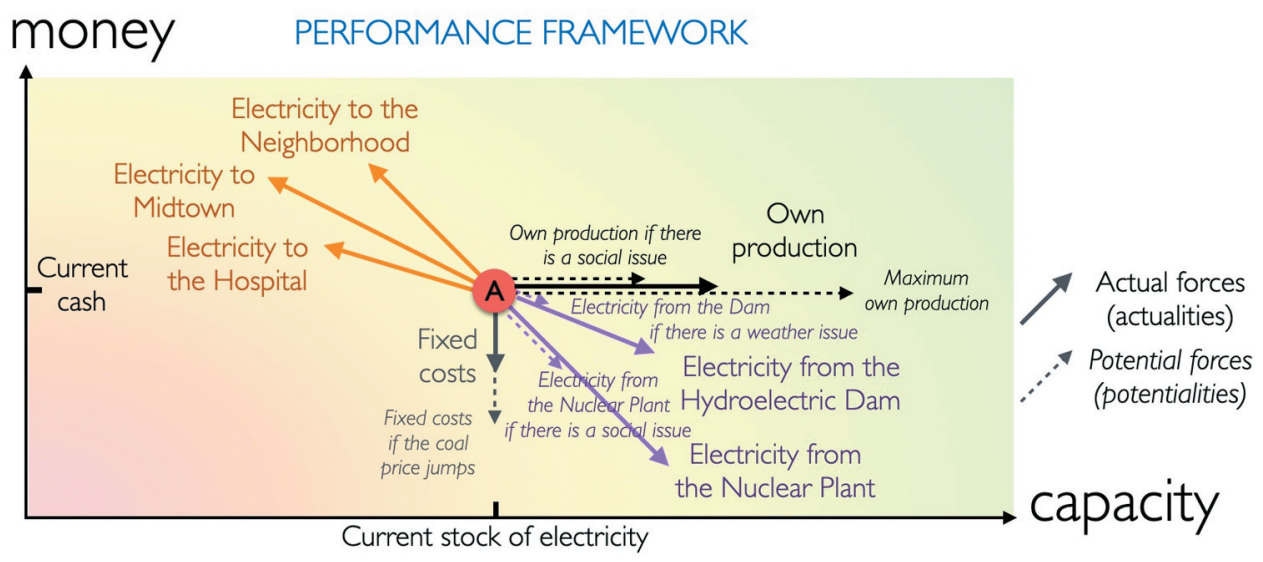

Figure 16. The performance framework: a balanced net of forces. 


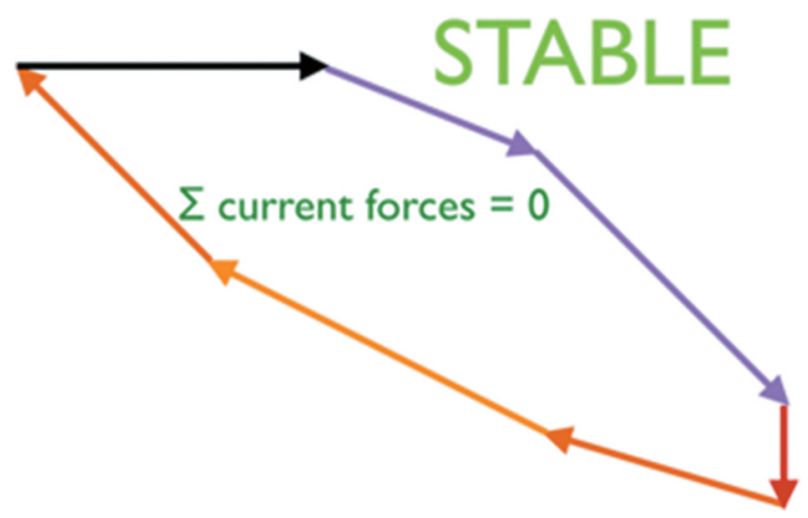

Figure 17. The balance net of forces of the power station.

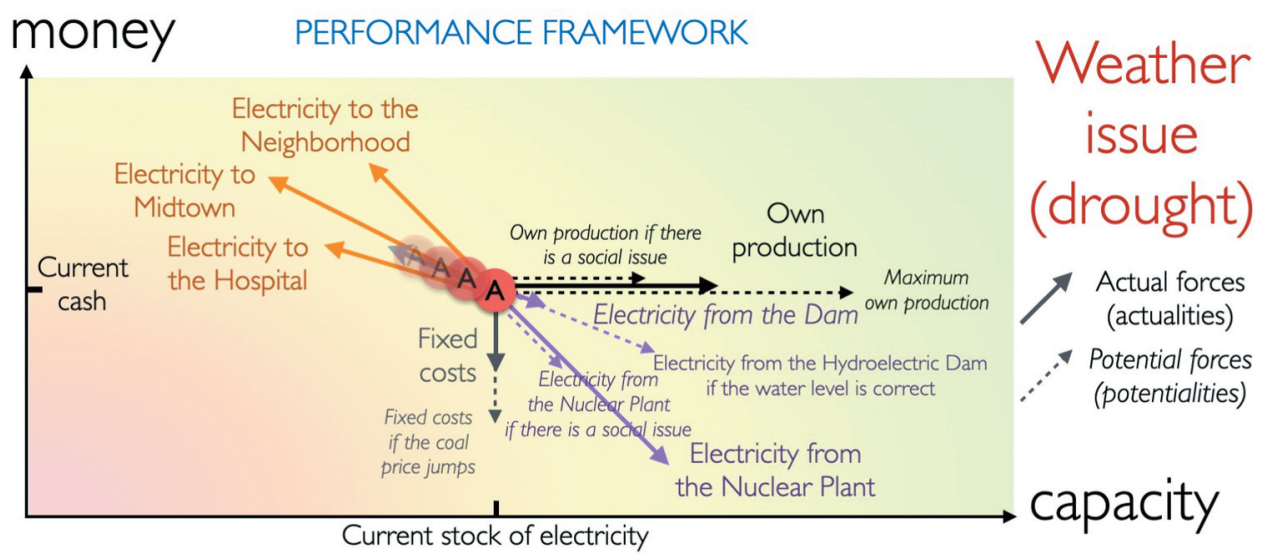

Figure 18. The performance framework: an unbalanced net of forces.

maintained for long due the limited stock of stored electricity. There may be option to make it a sustainable situation (batteries, distributed storage on the electricity grid, etc.) but this is not the point of this paper. Consequently, the power plant should find a way to bring a balance situation again. In that perspective, the power

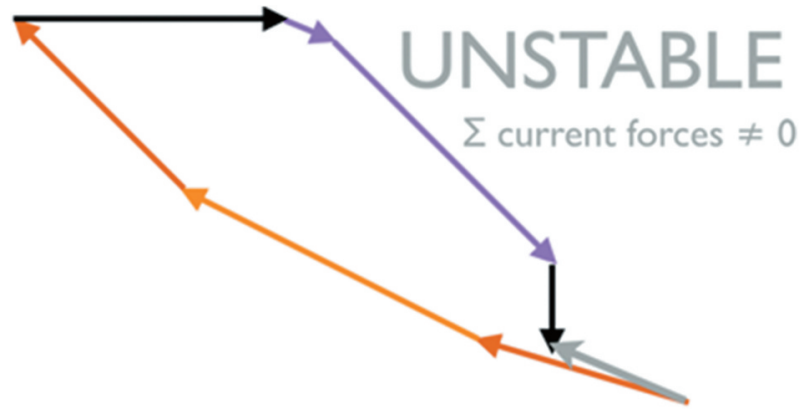

Figure 19. The unbalance net of forces in the case of instability. 
plant could either search for means to expand its capacity to deliver electricity (purchase more electricity from other providers or increase its own production capacity) or reduce the quantity of electricity delivered to its clients. In that last case, the next question concerns the choice of the impacted customers. Within the current performance framework, there is no precise criterion to use to make that choice. It possibly implies to extend the current performance framework with other performance dimensions in order to support the refinement of the decision process. For instance, it could be relevant to look at the criticality of the energy delivery. This might bring another performance aspect in the decision system. Figure 20 illustrates this:

Optimistically, that approach is not only dedicated to define and monitor the performance trajectory of a system (in the previous example, the system is the power plant) in its performance framework, but it may also provide some additional features:

First of all, it could help to draw "what if" scenarios in a very productive way. Users could select potentialities (according to their will, their belief, probabilities, etc.) and visualize the consequence of the set of selected potentialities.

Second, it could also provide the users with several sets of potentialities to trigger in order to reach the target position(s) in the performance framework (assuming that the user could be able to define these positions).

Third, this approach could also be used to identify reachable part of the performance space considering the known actual and potential forces. This would be a way to define for the users' goals that they did not even know they actually could target.

The use-case presented above, as already mentioned, is a pedagogical example and should not be considered as a demonstrative example. However, it is intended to help the reader to get the whole vision of the approach. The main concepts and principles have been introduced and located one relatively to each other through that use-case. Some important elements though have not been considered. For instance, the collect of data, required to perform the potentialities modelling has not been considered. Similarly, the formal way to value the impact of potentialities (e.g. the absolute variation of the intensity

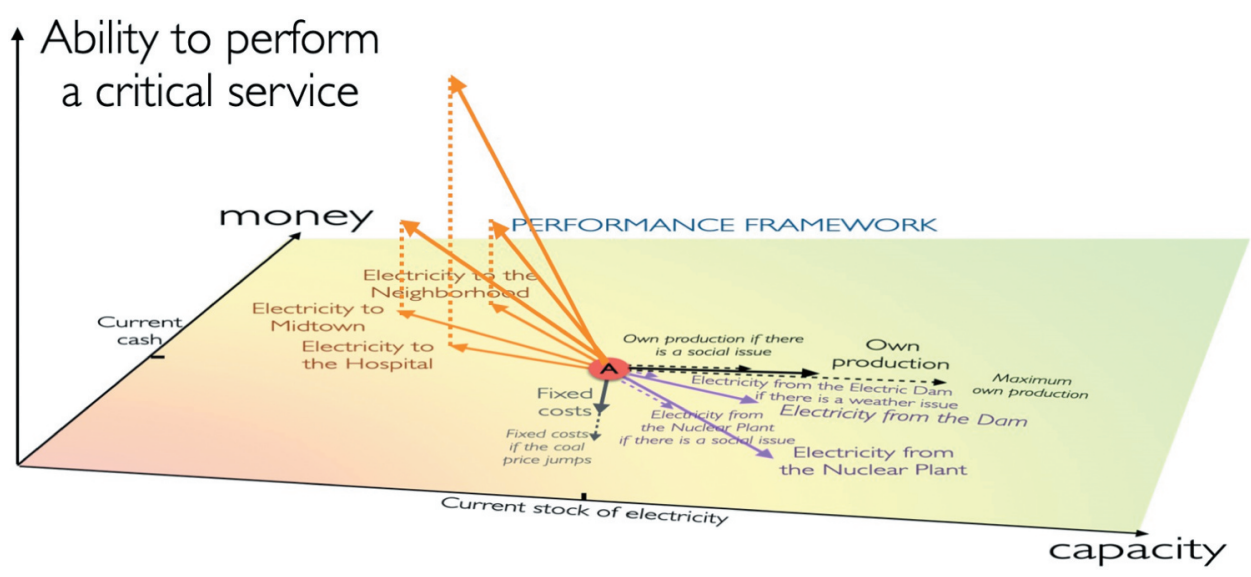

Figure 20. The use of other dimensions to refine the decision-making process. 
of fixed costs) have been considered as known and accessible. This is obviously a limitation to the realistic aspect of the use-case but not to its instructional and didactic main purpose. Nevertheless, the presented use-case shows that the Physics Of Decision approach is not only focusing on identification and assessment of risks and opportunities, it is also fully dedicated to mitigation and monitoring phases. It allows simultaneously to focus on (i) the understanding of the system and its instable environment, (ii) the modelling of options and their consequences, and (iii) study the combination of these options and make the best choice according to the current level of knowledge.

\section{Discussion}

This research work can be considered as deeply interdisciplinary by nature. On the one hand it can benefit from a large number of scientific domains (contributors). But on the other hand, a lot of scientific domains can also take advantage of the results of that decision-making theory (beneficiaries).

Regarding contributors, obviously physics stand at the forefront for its root position in the force-based paradigm. Not only Physics could contribute for the question of forces, trajectory and movement, but also in the next steps for the energy point of view (to model the cost of a move), and furthermore for the solid point of view: how the system can change its own attributes (i.e. its shape from the physics perspective) to optimise (max-imise or minimise) the susceptibility to that characteristic, and thus the impact of the force. The analogy can be to increase or decrease the surface to the wind or absorb the impact of a collision. In the scope of contributors, mathematics could also be a critical one. Actually, both the susceptibility and performance spaces can be seen as vector spaces (potentially groups, rings or fields). In the first one, the vectors are the decisions (which change the nature of the system or its environment) while in the second, the vectors are risks and opportunities (which change the performance of the system). The question of the potential morphisms between these two spaces is at the heart of that approach: Is there a chance to find some laws or rules, for some systems and some potentialities, that define the links between the two spaces (just like the trajectory of a ball can be defined on the basis of its surface, weight, speed and angle). Mathematics should also be considered as a high-level potential contributor. Actually, the vector space nature of both the susceptibility and performance spaces obviously open the door to mathematical deep considerations such as: what could be the nature of morphisms between the two spaces? Obviously, as decision support for performance management is not dedicated to one scientific domain, all domains related to that question of 'decision for performance' can be considered as a contributor. For instance, management science, social science, opera-tional research or more broadly industrial engineering can deeply contribute to that question.

Regarding beneficiaries, economics and management sciences could be very interesting application domains, especially because it is easy to get data and because it would be very impactful. Think about being able to define the trajectory of a start-up based on its profile and some of the environment characteristics. Medicine could also be a very interesting domain to investigate considering that physiological data could be collected (for the susceptibility framework) as well as data about the way of life of the patient (for the performance framework). It would be amazing to be able to discuss the 
trajectory of a patient in terms of vital performance based on his/her health data and lifestyle. The final step of this could be the exploitation of DNA as the susceptibility framework. Physics has been mentioned previously as an obvious contributor, but what about being able to describe a composite material in its susceptibility framework and to characterise in that framework the potential physical treatments that could be inflicted to the material? It would open the door to assess its performance in the performance framework and to anticipate the consequences of various treatments on these performances. The domain of crisis management, where the crisis system could be represented in its susceptibility framework to anticipate what actions and decision could have a benefit on the crisis situation, as presented in (Benaben et al., 2019a). Basically, any domain where decision-making is a critical issue for performance management could be an application domain of the approach presented in this article: anticipating the performance of a material with regards to its nature and the inflicted stress, team management, education, etc.

There is also another very significant perspective to this topic: the definition of the satisfying performance area. As presented earlier (see Figure 13), the target area can be a blurry zone of the performance space. However, there are plenty of other visions that could be relevant: a single plot could be a precise target, a subspace representing a combination of low/high barriers on the performance dimensions could be relevant as well, even a satisfying surface, linking values from the different dimensions could be relevant. This also brings the question of the 'density of the performance space' which somehow could show that some part of the performance space are more or less accessible (depending on time of course) via the inflicted forces. Conversely, some parts of the performance space may be almost inaccessible via any kind of combination of the available identified forces.

Beyond these perspectives, there are some strong limitations and constraints that must be considered as soon as possible. For instance, the question of independence of forces is at the core of the reasoning: based on which criteria is it possible to sum forces? At this stage, it seems that the deep and precise impact of forces on the observed system could be an interesting avenue. For instance, an event that would only affect the building of a company, while another force is inflicted on the research investment of the company, could legitimately be considered as independent due to the fact that they affect independent dimension of the system (roughly speaking, their distributions have no intersection within the susceptibility framework). The question of visibility is also a critical one: what about hundreds of potentialities (vectors) visualised in a twenty dimensions performance framework? There are plenty of options to deal with that question (dimension reduction like principal component analysis, smart visualisation tools like immersive analytics, etc.) but studies are not done yet.

Finally, the question of data gathering, already mentioned in section 4 is obviously a critical issue. However, the position of this paper is to claim that the presented approach, even if strongly and obviously depending on data, is a direct competitor to rough and direct data management technics. Consequently, this approach is supposed to be applied in context where data is available. 


\section{Conclusion}

The presented approach aims at using data to understand a given situation (through the design of a susceptibility model) and to exploit that vision of the situation to infer decisions (through the study of the performance model). These models (and the associated model-ling frameworks) are based on a theoretical framework, merging Data Sciences (especially data analytics) and Industrial Engineering (especially model-driven engineering). Data science is used mainly to build the susceptibility model and to define the impact matrix and the impact vectors of characteristics onto elements of the studied system. Industrial Engineering is used to contribute to the definition of the impact matrix and vector and also to exploit the obtained susceptibility models to create the performance model. The final results would be to assist the decision-makers in helping organisations reach some target area in the performance framework, or even to define the reachable areas in the perfor-mance framework (and how to reach them). The next steps will be focused on two parallel subjects: (i) the study of the algebraic vision of the model to deduce how the considered susceptibility and performance spaces could be formally connected and how the morph-isms between these vector spaces could be inferred and potentially defined, (ii) the study of complex use-cases, for instance through a simulation approach, to collect credible scenarios.

\section{Notes}

1. https://dictionary.cambridge.org/dictionary/english/instability (last acceded 25th of August 2020), which is consistent in the connection to 'uncertainty' with https://www. merriamwebster.com/dictionary/instability (last acceded 25th of August 2020)

2. https://dictionary.cambridge.org/dictionary/english/uncertainty (last acceded 25th of August 2020)

3. the question of the way to define these values is not addressed in this paper. This target can be a precise set of KPIs values, a volume (due to intervals for these KPIs), an equi-satisfaction surface, and so on.

4. https://en.wikipedia.org/wiki/DIKW_pyramid (last acceded on the $25^{\text {th }}$ of August 2020)

5. The knowledge representation on Figure 5 will not be shown in the following figures as it is considered implicitly present.

\section{Acknowledgments}

The contributions described in this article have been initially presented during IESM 2019 conference (Benaben, et al., 2019a). This work has been selected among the presented articles to be significantly extended and submitted for a special issue of the Enterprise Information Systems journal. The authors would like to thank the organizers of the conference to select their paper for that special issue.

\section{Disclosure statement}

No potential conflict of interest was reported by the authors. 


\section{ORCID}

Frederick Benaben (D) http://orcid.org/0000-0002-1676-6524

Benoit Montreuil (iD) http://orcid.org/0000-0001-9909-9212

Matthieu Lauras (D) http://orcid.org/0000-0003-2901-4038

\section{References}

Ackoff, R. 1989. "From Data to Wisdom." Journal of Applied System Analysis 16: 3-9.

Bastin, L., D. Cornford, R. Jones, G. Heuvelink, E. Pebesma, C. Stasch, S. Nativi, P. Mazzetti, and M. Williams. 2013. "Managing Uncertainty in Integrated Environmental Modelling: The UncertWeb Famework." Environmental Modelling and Software 39: 116-134. doi:10.1016/j. envsoft.2012.02.008.

Bell, T. 1989. "Managing Risk in Large Complex Systems - Special Report." In Spectrum.

Benaben, F., A.-M. Barthe-Delanoë, M. Lauras, and S. Truptil. 2014. "Collaborative Systems in Crisis Management: A Proposal for A Conceptual Framework." In Working Conference on Virtual Enterprise, 396-405. The Netherlands: Springer, IFIP, Amsterdam.

Benaben, F., J. Li, I. Koura, B. Montreuil, M. Lauras, W. Mu, and J. Gou, "A Tentative Framework for Risk and Opportunity Detection in A Collaborative Environment Based on Data Interpretation", Proceedings of 52nd HICSS'19, Hawaii, USA, 2019b.

Benaben, F., M. Lauras, B. Montreuil, L. Faugère, J. Gou, and W. Mu "Physics of Organization Dynamics: An Al Framework for Opportunity and Risk Management", proceedings of IESM 2019a, IEEE, Shanghai, China, 2019.

Clifton, J. J. 1990. "Hazard Prediction", in Keller." In Disaster Prevention, Planning and Limitation, Disaster Prevention and Limitation Unit, edited by Z. A and H. C. Wilson. University of Bradford and The British Library.

Covello, V. T. 1987. "Decision Analysis and Risk Management Decision Making: Issues and Methods." Risk Analysis 7 (2): 131-139. doi:10.1111/j.1539-6924.1987.tb00978.x.

Covello, V. T., and M. W. Merkhofer. 1993. Risk Assessment Methods - Approaches for Assessing Health and Environmental Risks. New York, NY: Plenum Press.

Dickinson, l., "National Resilience Extranet Common Operational Picture", Niteworks report, Ref $\mathrm{N}^{\circ}$ : NW/Pj/ResComms/4902a, 2013.

Dietz, J., E. Proper, and J. Tribolet. 2009-2014. The Enterprise Engineering Series. Springer. Edwards,

P., and P. Bowen. 2005. Risk Management in Project Organisations. Oxford, UK: Elsevier. Gandomi,

A., and M. Haider. 2015. "Beyond the Hype: Big Data Concepts, Methods, and Analytics." International Journal of Information Management 35 (2): 137-144. doi:10.1016/j. ijinfomgt.2014.10.007.

Gao, Q., S. Guo, X. Liu, G. Manogaran, N. Chilamkurti, and S. Kadry. 2020. "Simulation Analysis of Supply Chain Risk Management System Based on loT Information Platform." Enterprise Information Systems, Taylor\&Francis 14 (9-10): 1354-1378. doi:10.1080/17517575.2019.1644671.

Gunn, R., and W. Williams. 2007. "Strategic Tools: An Empirical Investigation into Strategy in Practice in the UK." Strategic Change 16 (5): 201-216. doi:10.1002/jsc.799.

Hambly, E. C., and E. A. Hambly. 1994. "Risk Evaluation and Realism, Proceedings of the Institution of Civil Engineers." Civil Engineering 102 (2): 64-71.

Ho, S. S. M., and R. H. Pike. 1992. "The Use of Risk Analysis Techniq ues in Capital Investment Appraisal." In Risk: Analysis, Assessment and Management, edited by J. Ansell and F. Wharton. Chichester: John Wiley \& Sons.

Ho, W., T. Zheng, H. Yildiz, and S. Talluri. 2015. "Supply Chain Risk Management: A Literature Review." International Journal of Production Research. 53 (16): 5031-5069. doi:10.1080/ 00207543.2015 .1030467$.

Jagadish, H., J. Gehrke, A. Labrinidis, Y. Papakonstantinou, J. Patel, R. Ramakrishnan, and C. Shahabi. 2014. "Big Data and Its Technical Challenges." Communications of the ACM 57 (7): 86-94. doi:10.1145/2611567. 
Kletz, T. A. 1990. Critical Aspects of Safety and Loss Prevention. London: Butterworths.

Lave, L. B. 1986. "Approaches to Risk Management: A Critique." Risk Evaluation and Management. 1986. New York, NY: Plenum Press.

Li, J., F. Benaben, J. Gou, and W. Mu W. 2018. "A Proposal for Risk Identification Approach in Collaborative Networks considering Susceptibility to Danger." In Working Conference on Virtual Enterprise, 74-84. Cardiff, UK: Springer, IFIP.

Olsson, R. 2007. "In Search of Opportunity Management: Is the Risk Management Process Enough?" International Journal of Project Management 25 (8): 745-752. doi:10.1016/j.ijproman.2007.03.005.

Ribeiro, J. P., and A. Barbosa-Povoa. 2018. "Supply Chain Resilience: Definitions and Quantitative Modelling approaches-A Literature Review." Computers \& Indus. Engineer 115: 109-122. doi:10.1016/j.cie.2017.11.006.

Rodrigues Da Silva, A. 2015. "Model-driven engineering: A survey supported by the unified conceptual model" Computer Languages, Systems and Structures, Elsevier, vol. 43, pp. 139-155.

Rowley, J. 2007. "The Wisdom Hierarchy: Representations of the DIKW Hierarchy." Journal of Information and Communication Science 33 (2): 163-180. doi:10.1177/0165551506070706.

Rus, I., and M. Lindvall. Knowledge Management in Software Engineering. IEEE Software: Vol. 19,issue 3, 26-38. 2002.

Taleb, N. 2007. The Black Swan - The Impact of the Highly Improbable. New York: Random House.

Taleb, N. 2012. Antifragile - Things that Gain from Disorder. New York: Random House.

Tolk, A. 2005. "An Agent-based Decision Support System Architecture for the Military Domain." Intelligent Decision Support Systems in Agent-Mediated Environments 115: 187-205.

Vernadat, F. 1996. Enterprise Modeling and Integration, Principles and Applications. Springer, Chapman \& Hall.

Vernadat, F. 2002. "Enterprise Modeling and Integration (EMI): Current Status and Research Perspectives." Annual Reviews in Control 26 (1): 15-25. doi:10.1016/S1367-5788(02)80006-2.

White, D. 1995. "Application of Systems Thinking to Risk Management: A Review of the Literature." Management Decision 33 (10): 35-45. doi:10.1108/EUM0000000003918.

Zeng, B., and P. Yen. 2017. "Rethinking the Role of Partnerships in Global Supply Chains: A Risk-based Perspective." International Journal of Production Economics 185: 52-62. doi:10.1016/j. ijpe.2016.12.004.

Zheng, X., and L. Zhang. 2020. "Risk Assessment of Supply-chain Systems: A Probabilistic Inference Method." Enterprise Information Systems 14 (6): 858-877. doi:10.1080/17517575.2020.1762004. 